\title{
ПРОСТРАНСТВЕННЫЕ ПУЛЬСАЦИИ НАСЕЛЕНИЯ СОВРЕМЕННОЙ РОССИИ
}

\author{
Рецензия на коллективную монографию «Между домом и... домом. \\ Возвратная пространственная мобильность населения России» \\ НИКИТА МКРТЧЯН
}

\begin{abstract}
Книга, основанная на анализе всех доступных на сегодняшний день данных о миграции в России, рассказывает о многообразии форм пространственных перемещений, не связанных со сменой постоянного места жительства. Где живет, работает и просто проводит время человек, формально не меняя адрес проживания, с чем связаны эти регулярные перемещения в пространстве, почему это не менее важно, чем традиционное рассмотрение миграции как «переезда» надолго или насовсем, для понимания жизни в стране, ее регионах и поселениях - таков далеко не полный перечень вопросов, поставленных коллективом авторов.
\end{abstract}

Ключевые слова: пространственная мобильность населения, урбанизация, отходничество, дачный феномен, сельско-городской континуум.

Название монографии, подготовленной коллективом российских географов ИГ РАН и Географического факультета МГУ им. М.В. Ломоносова, как нельзя лучше указывает на пространство пульсаций населения в современной России. В этих пульсациях участвует огромное число людей, многие из них живут на два дома. Отходник или, как принято его называть сейчас, временный трудовой мигрант совершает регулярные поездки на работу между «главным» домом в селе, поселке или небольшом городе и временным жильем в крупном центре. В обратном направлении перемещается дачник, оставляя квартиру в городе и перемещаясь в пригородный дом/полудом/домик с брендовым названием «дача». Если поездки на работу или учебу совершаются ежедневно, дом, как бы он ни назывался, остается всего одним, его покидают утром и возвращаются вечером.

Книга содержит три части. Первая, небольшая по размеру, но весьма важная по своей теоретической значимости, посвящена характеристике процессов и концепций, которые рассматриваются авторами как «миграционный и поселенческий фон», на котором разворачиваются возвратные перемещения людей. Здесь читатель, если он еще до этого не был знаком с исторической эволюцией мобильности и расселения, получает представление о мобильном переходе У. Зелинского, теории стадиальной урбанизации Дж. Джибса, а также общей направленности миграции в конце XX - начале XXI века. Здесь же читатель знакомится с современным состоянием концепции сельско-городского континуума. Если теория урбанизации противопоставляет сельскую местность городу, крупные города малым, то концепция сельско-городского континуума показывает их тесную связность. В современной России конструкция континуума не только позволяет рассмотреть движение населения внутри него, но и, например, понять, почему мигранты извне выбирают для жительства сельскую местность вблизи городов, а сельские пригороды в результате прирастают населением быстрее, чем сами города.

НИКИТА ВЛАДИМИРОВИч МКРТчЯН (nmkrtchyan@hse.ru), НАЦИОНАЛЬНЫЙ ИССЛЕДОВАТЕЛЬСКИЙ УНИВЕРСИТЕТ «ВЫСШАЯ ШКОЛА ЭКОНОМИКИ», РОССИЯ.

РЕЦЕНЗИЯ ПОСТУПИЛА В РЕДАКЦИЮ В АВГУСТЕ 2018 Г. 
Многое из того, что содержит первая часть книги, ее авторы А.И. Трейвиш и Т.Г. Нефедова уже представляли читателям в виде отдельных статей, но в книге это не просто «повторение пройденного». Посвящая книгу возвратной мобильности, авторы не могли не сказать и о безвозвратной, результатом которой, собственно, и стала современная урбанистическая структура населения России и сформировался сельско-городской континуум.

Вторая часть книги с емким названием «В город за работой» содержит, пожалуй, наиболее глубокий и всесторонний в нашей литературе анализ трудовой мобильности в России 2000-2010-х годов. Начинается она с экскурса в богатую и достаточно детально изученную историю отходничества в России, здесь авторы опираются преимущественно на вторичные источники. Но уже вторая глава этой части книги дает глубокое представление о предпосылках современного отходничества, понять которые, наверное, невозможно без детального знания географии России не на уровне регионов, а на уровне всего множества городов и территорий страны, которые близки к локальным рынкам труда. Особую весомость изысканиям временной трудовой миграции придает то, что они базируются не только и не столько на камеральных, но и на полевых исследованиях, методика которых в общих чертах изложена в отдельном параграфе.

Подробнейший анализ всей доступной (на дату подготовки публикации) статистики миграции на региональном и муниципальном уровнях приводятся в параграфах, подготовленных Т.Г. Нефедовой и Е.В. Антоновым. Опять же, здесь не обходится без привлечения статистики долговременной миграции, которая разрабатывается и публикуется более подробно, чем данные о временных трудовых перемещениях. Е.В. Антонов проделал огромную работу по визуализации и анализу данных Всероссийской переписи населения 2010 г. - единственному доступному источнику, позволяющему изучать направления отходничества в современной России на муниципальном уровне. Результат - уникальные карты, демонстрирующие:

1. распространенность трудовой мобильности в пригородах крупных городов и на внутренней периферии. Единственная проблема - данные переписи не позволяют отделить суточную (маятниковую) миграцию от других форм мобильности, прежде всего - от временной трудовой миграции. Суточная миграция, по числу участвующих в ней существенно превосходит отходничество и концентрируется преимущественно в пригородных зонах. Хочется надеяться, что в переписи 2020 г. эти виды трудовой мобильности удастся разделить, но для этого в ее программу надо добавить вопрос о частоте посещений дома;

2. географию «сбора» трудовых мигрантов крупнейшими центрами: Москвой, СанктПетербургом, тюменскими «Северами» и др. Только перепись с ее всеобщим охватом населения позволяет вести такие расчеты, и поклон Росстату, что он предоставил свободный доступ к ее детальным пространственным данным.

Вообще исследователи ИГ РАН традиционно больше внимания уделяют изучению Европейской части страны, в чем нельзя их упрекнуть: за Урал не дотянулся своей исследовательской дланью даже В.П. Семенов-Тян-Шанский в нетленной работе «Город и деревня в Европейской России». Тем более ценно, что в книге «Между домом и... домом», 
а еще ранее в своей диссертации Е.В. Антонов представил анализ городских рынков труда и трудовой мобильности на Урале, в Сибири и на Дальнем Востоке.

А.Г. Махрова и П.Л. Кириллов продолжают изучение маятниковой миграции в Московской агломерации по данным сотовых операторов, что не часто встречается в российских исследованиях не только в силу затрудненного доступа к этим данным, но и ввиду чрезвычайной трудоемкости работы с ними. Результат этого исследования состоит не только в изучении непосредственно суточной трудовой мобильности, но и углублении наших представлений о границах агломерации, взаимосвязи мобильности с транспортной сетью. Последнюю, кстати, на примере в основном все той же столичной агломерации всесторонне анализирует А.С. Неретин. Обе части работы имеют, на мой взгляд, огромный потенциал для применения на практике.

Завершающие главы К.В. Аверкиевой и Т.Г. Нефедовой, посвященные трудовой мобильности в сельской местности, в основном базируются на данных полевых исследований. Чтобы подойти к этой проблеме, авторы на примере территорий-ключей (13 муниципальных районов 5 регионов Нечерноземья и села в Ставрополье) изучают экономику, рынки труда и лишь затем - возвратную мобильность. Читатель, помимо анализа пространственной мобильности, узнает, что в селе Нечерноземья уже мало кто занят сельским хозяйством, а на юге страны бурное развитие зерноводства привело к «бегству» вчерашних крестьян в города и в отход.

Третья часть книги «Дачи, дачники и дачеведение» тоже про мобильность, но в обратном направлении. Несмотря на то, что с дачеведением усилиями его основоположников (А.И. Трейвиша, Т.Г. Нефедовой и А.Г. Махровой) заинтересованный читатель уже в какой-то мере знаком, в книге собраны и переосмыслены все прежние теоретические наработки, приведен достаточно подробный экскурс в историю. Приведен подробный анализ методов исследования дач и дачников, включая новейшие: использование данных сотовых операторов, дешифрирование космоснимков (при технической и интеллектуальной поддержке А.А. Медведева) и др.

По давно сложившемуся разделению многолетних исследовательских интересов трансформацию традиционных дач в коттеджные субурбии в пригородах Москвы и СанктПетербурга представляет читателю А.Г. Махрова. Т.Г. Нефедова расширяет границы дачной России за пределы пристоличных областей и не только в Нечерноземье, но и, например, на Ставрополье. Дальние дачи москвичей и петербуржцев - пример реосвоения глубинной России, смены ее хозяйственной специализации с сельскохозяйственной на преимущественно рекреационную. Отметим, что авторы книги - сами «практикующие» дачники, много лет на собственном примере и примере коллег изучающие горожан в костромской глубинке.

«Дачная» часть книги изобилует не только и не столько статистическими данными, сколько анализом личных визуальных наблюдений по следам многочисленных поездок, картами, фотоматериалами. Все многообразие российских дач, наверное, данная книга все равно не вместила, в ней, например, не получила развития тема «дачной деградации», с которой, возможно, столкнется Россия в ближайшие десятилетия. Но, что неоспоримо, о «втором» доме горожанина читатель получит исчерпывающее представление. 
Книга дает максимально полную картину движения населения, не описываемого данными статистики. Этих возвратных движений много больше, чем мы можем видеть из регулярных публикаций Росстата. Чем кратковременней поездки «между домом и домом», тем меньше их расстояние, тем больше «мобилей», участвующих в них и тем неуловимее они для камеральных исследователей.

\section{ЛИТЕРАТУРА}

Между домом и... домом. Возвратная пространственная мобильность населения России (2016) / Под редакцией Т.Г. Нефедовой, К.В. Аверкиевой, А.Г. Махровой. М.: Новый хронограф. 504 с. 


\title{
SPATIAL PULSATIONS OF THE POPULATION OF MODERN RUSSIA \\ Review of the book «Between home and... home. Recurrent spatial mobility of the population in Russia»
}

\section{NIKITA MKRTCHYAN}

\begin{abstract}
The book, based on an analysis of all currently available data on migration in Russia, tells the reader about all the diversity of forms of spatial displacements that are not related to a change of permanent residence. Where does a person live, work and just spend time, without changing his address of residence? What is the reason for these regular movements in space? Why is it no less important than the traditional understanding of migration as "moving" for a long time or for all time, to understand life in the country, its regions and settlements? This is a far from complete list of the questions posed by the team of authors.
\end{abstract}

Key words: spatial mobility of population, urbanization, otkhodnichestvo (seasonal labor migration), dacha phenomenon, rural-urban continuum.

\footnotetext{
Nikita MKRTChyan (nmkrtchyan@hse.ru), NATIONAL ReSEARCH University Higher School of EcONOMICS, RUSSIA.

DATE RECEIVED : AUGUST 2018.
}

\section{REFERENCES}

Mezhdu domom i... domom. Vozvratnaya prostranstvennaya mobil'nost' naseleniya Rossii

[Between home and... home. Reccurent spatial mobility of the population in Russia] (2016) / T.G. Nefedova, K.V. Averkieva, A.G. Makhrova, eds. Moscow: Novyy khronograf. 504 p. 